\title{
FATORES RELACIONADOS AO SUPERENDIVIDAMENTO DO CONSUMIDOR DE BAIXA RENDA
}

\section{ARTIGO ORIGINAL}

GONZAGA, Samara Coelho ${ }^{1}$

GONZAGA, Samara Coelho. Fatores relacionados ao superendividamento do consumidor de baixa renda. Revista Científica Multidisciplinar Núcleo do Conhecimento. Ano 05, Ed. 04, Vol. 07, pp. 17-25. Abril de 2020. ISSN: 2448-0959, Link de acesso: https://www.nucleodoconhecimento.com.br/lei/superendividamentodo-consumidor

\section{RESUMO}

Uma das grandes preocupações sobre o desenvolvimento e globalização da sociedade é o excesso de dividas, ou que pode ser denominado como o superendividamento, com o propósito de adquirir produtos que são muitas vezes inviáveis devido ao poder aquisitivo, cada vez mais as pessoas recorrem a métodos de crédito fácil, resultando em um grande problema econômico e social. Com base no contexto realizado que a presente pesquisa tem o objetivo de demonstrar os fatores e aspectos que estão relacionados a causa do superendividamento nos consumidores de baixa renda. A metodologia adotada é um estudo bibliográfico que teve como base as literaturas que possuem relação ao tema e assunto pesquisado e teve como intuito os autores mais qualificados do meio acadêmico e citados. Dessa forma, a partir do conteúdo desenvolvido foi possível constatar que os consumidores de baixa renda são os mais afetados pelo superendividamento, tendo em vista os problemas sociais enfrentados no baixo poder aquisitivo e fazendo uso das ofertas fáceis de crédito, através da ausência de uma legislação determinante com relação ao assunto e por ser influenciado através das técnicas e práticas de marketing de consumo.

\footnotetext{
${ }^{1}$ Graduada em Direito pela Universidade Estácio de Sá.
} 
Palavras-chave: Superendividamento, baixa renda, consumidores.

\section{INTRODUÇÃO}

A presente pesquisa possui como tema o superendividamento nas relações de consumo que afeta o dia a dia de uma parcela determinante da população de baixa renda, demonstrando então os fatores relacionados a essa ocorrência e a justificativa do desenvolvimento desse fato.

Com base na temática apresentada algumas dúvidas foram levantadas e realizaram o direcionamento da presente pesquisa:

- Quais os aspectos relacionados ao superendividamento dos consumidores no âmbito das relações comerciais?

- Como o consumidor de baixa renda consegue ser afetado de maneira mais crítica pelas causas associadas ao superendividamento?

A partir do código de defesa do consumidor, foi reconhecido que o consumidor se tornou a parte mais vulnerável tecnicamente na relação comercial existente, devido ao resultado de problemas apresentados pelas violações do código, como o da solidariedade, da transparência e da boa-fé objetiva, onde os princípios éticos e legais não são respeitados e ocorrem com o endividamento do consumidor sendo que o mesmo não possui as condições econômicas para pagar o que foi contratado.

Segundo dados de uma pesquisa realizada pela Fundação Getúlio Vargas (FGV), ocorreu entre 2003 e 2009, o surgimento da nova classe média C, onde se tinha cerca de $20,5 \%$ da população, determinando um ponto dominante econômico do ponto de vista do consumo, por concentrar cerca de $46,24 \%$ do poder de compra (NERI, 2010). É possível constatar com base no contexto realizado então, que o marketing de consumo foi propagado de modo exponencial para que os clientes fossem compelidos a realizar a compra de produtos e serviços sem a devida necessidade. O marketing de consumo segundo Kotler (2000), tem o objetivo de atingir o consumidor final e 
tornar a venda supérflua, fazendo com que não se pratique o relacionamento entre cliente e vendedor.

Dessa forma, com base nas informações relacionadas que o presente trabalho possui o objetivo de analisar e apontar os fatores que podem ser relacionados ao superendividamento dos consumidores de baixa renda.

A metodologia abordada será a realização de uma pesquisa bibliográfica por meio da revisão da literatura acadêmica. Para realização e fundamentação deste trabalho ira ser realizado então uma revisão bibliográfica, utilizando como base artigos, periódicos, livros, etc., qualquer material de índole confiável e de forma a contribuir com o conteúdo exposto no trabalho, as bases de dados para realização deste trabalho têm como origem CAPES, SciELO (Scientific Electronic Library Online) e no banco de dados de universidades brasileiras como a USP Universidade de São Paulo) e UNICAMP (Universidade de Campinas), realizando pesquisas com foco em: Consumidores de baixa renda; Superendividamento; Marketing de consumo; Proteção do consumidor. Após o levantamento das informações foi realizado a avaliação do material obtido e separado aqueles para uso na aplicação do trabalho, compilando as principais informações.

\section{DESENVOLVIMENTO}

O endividamento crônico é um fenômeno generalizado nas sociedades de consumo, justificado pela facilitação do acesso ao crédito, torna-se mais democrático o pagamento através de parcelamentos e conta com o resultado do superendividamento no Brasil (MARQUES; CAVALLAZZI, 2006). No caso do Brasil, nenhuma legislação prevê endividamento excessivo. Na ausência de uma fonte nacional oficial para a análise da instituição, os doutrinadores do país confiam na lei francesa para nomear dívidas excessivas e descrevê-las no ordenamento jurídico do país de origem.

A definição de maior prestígio, redigida pela jurista Marques (2011), refere-se ao superendividamento como a total impossibilidade de o consumidor, o indivíduo, o 
devedor, o leigo a pagar fielmente suas dívidas atuais e futuras (com exclusão das dívidas contra autoridades fiscais, crimes e alimentos).

As características do superendividamento geralmente dependem de uma definição atualmente ausente da legislação brasileira. Portanto, os advogados nacionais aplicam o direito de liquidação para fazer suposições sobre as características da dívida excessiva e os possíveis beneficiários da lei futura (MARQUES, 2011). Dessa forma, o que pode ser determinado e relacionado em algumas situações é a relação do consumo e a proteção do consumidor. O consumo implica a exclusão de produtores, fabricantes e pessoas jurídicas em geral, que tenham uma abordagem mais restritiva do que a Lei de Proteção ao Consumidor, pois eles não protegem uma pessoa coletiva. Essa limitação diz respeito à regulamentação legal de recuperação judicial e insolvência de empresas.

$\mathrm{Na}$ lei francesa, o superendividamento no Brasil não se aplica aos devedores que, se possível, podem pagar suas dívidas adequadamente (PAULA, 2011). Portanto, é caracterizado como uma pessoa que usa o crédito para comprar bens e serviços e se torna excessivamente criminosa até que apela ao judiciário para ajudá-la a cumprir suas obrigações ao longo das negociações.

A situação financeira das pessoas em atraso sugere uma impossibilidade legal na lei francesa, na medida em que o devedor não possui um custo mínimo legalmente estabelecido. Portanto, para analisar a situação da dívida, é necessária uma análise de cada caso, levando em consideração os recursos das pessoas endividadas, os ativos e a capacidade de pagar todas as dívidas, levando em consideração as necessidades básicas, a pessoa em questão e sua família.

Também é importante observar que, se o devedor puder pagar a dívida com fundos suficientes, ele não poderá ser considerado uma vítima da dívida. De acordo com a lei francesa, não há dívida excessiva se o devedor tiver prometido outros ativos além do seu local de residência, o que possibilita o pagamento total ou parcial do valor total da dívida (BAUDRILLARD, 2007). Essa limitação é idealmente aplicável em casos brasileiros. 
A doutrina francesa também estabelece a boa-fé como pré-requisito para ajudar pessoas com dívidas excessivas, não como o estado de ânimo do sujeito, mas o comportamento correto, cooperativo e adequado que corresponde à lealdade objetiva que existe sobre esse assunto. Todas as relações legais com o consumidor são herdadas indiretamente do art. 4ㅜ, inciso III, da lei de proteção dos direitos do consumidor.

O problema do superendividamento que se enfrenta não é apenas um caso isolado ou esporádico, resultado de incurabilidade ou de uma simples falta de controle sobre o consumidor, mas também um fenômeno global que preocupa legisladores e advogados de diferentes países, cujas consequências não se limitam à região, mas prejudica a saúde física e emocional dos devedores, afetando a sua dignidade como pessoa e, às vezes, destrói sua unidade familiar, o que tem consequências para a sociedade como um todo.

De acordo com o Núcleo de Defesa do Consumidor (NUDECON), a análise dos dados referente aos devedores e consumidores demonstra que:

[...] a) O número de devedores passivos é quatro vezes o número de devedores ativos (que gastam mais do que ganham) (b) os devedores devem para mais do que dois credores, (c) que a grande maioria não recebeu contrato e não recebe subsídio e / ou devido a uma situação imprevista - doença, desemprego, nascimento - em estado de endividamento, na acepção do art. 46 e 52 do Código do Consumidor mesmo após a conclusão da transação, d) apenas $21 \%$ dos entrevistados foram obrigados a fornecer uma garantia. Isso levou a conclusões, inclusive sobre a necessidade de falência do consumidor, a aplicação de direitos de revogação de ofertas de empréstimos (artigo 49 do $(D C)$ e a provocação da aplicação do artigo 4802 do código civil, o problema da dívida do consumidor (MARQUES; CAVALLAZZI, 2011, p. 14). 
Facilitar e promover o acesso ao crédito, como evidenciado nos últimos 20 anos, por meio da alta privatização de serviços básicos e públicos acessíveis a todos, sem distinção, bem como a implementação do marketing de consumo agressivo sobre empréstimos às famílias, através do novo poder da mídia tecnológica e a tendência à globalização, tendenciado em um crédito facilitado, simples e ilimitado em termos de tempo e custos, incluindo reduções nos benefícios da velhice, são os fatores que levam ao consumidor e sua família a um estado excessivo de endividamento no âmbito comercial.

O comportamento dos consumidores de baixa renda também mudou. Com o crescimento de classes modestas no Brasil, que se tornaram um mercado consumidor crescente, muitas empresas tiveram que se adaptar e planejar seus produtos para esse novo perfil.

O aumento da renda e o crescimento da oferta de empréstimos deram aos consumidores de baixa renda maior poder de compra e até estabeleceram a meta de pesquisa estratégica para melhor reconhecer esse segmento.

No Brasil, o mercado de baixa renda se mostra sendo muito promissor, com recursos e custos que os profissionais de marketing precisam entender para aceitar os produtos e serviços que oferecem.

Parente, Limeira e Barki (2008) apontam baixa autoestima e vulnerabilidade como características desse segmento. Pessoas que conhecem sua baixa renda já se sentem inferiores perante as ofertas de produtos e serviços. Além disso, existem outros casos de restrições que afetam a autoestima e, portanto, resulta a necessidade de adquirir crédito para consumo.

Castilhos (2007) considera o consumo de crédito como um meio de previsão. No entanto, Brusky e Fortuna (2002) também observam que o consumo de crédito para consumidores de baixa renda não é uma opção para previsão de renda, mas principalmente para manutenção da dívida. Ou seja, o consumidor é forçado a solicitar 
um novo empréstimo para controlar seu orçamento e manter as taxas do empréstimo anterior, além de realizar novas dívidas, determinando o superendividamento.

A tendência de escolher empréstimos e créditos fáceis é explicada pelo fato de que essa é a única alternativa para um consumidor com pouco acesso adquirir um produto. Um consumidor de baixa renda mal pode prestar atenção às taxas de juros integradas no financiamento e nos preços dos produtos, o que leva a sua dívida e pode levar a uma dívida excessiva.

Presume-se que o superendividamento seja um fenômeno decorrente de empréstimos irresponsáveis por empresas financeiras e não apenas uma quebra de contrato ou outra hipótese de insolvência, mas um problema social real que o sistema de justiça enfrenta com uma visão diferenciada. $O$ direito a indenização a esse respeito decorre da proteção jurisdicional que será oferecida a consumidores altamente endividados, levando em conta, em particular, a opinião de que a companhia financeira é insuficiente e empresta irresponsavelmente um empréstimo, sem verificação prévia de sua solvência.

No entanto, para se proteger de dívidas excessivas, se deve ser um consumidor sério considerado de boa-fé, com um superendividamento passivo atrasado e com uma insolvência comprovada. Os pagamentos em atraso ocorrem quando os consumidores atrasam suas obrigações, o que serve como um aviso de que o consumidor está endividado ou já tem dívidas excessivas. Com relação ao nível da dívida, não há como estabelecer um valor para a caracterização da dívida. Essa condição não depende da quantia devida, mas do fato de que sua renda é inferior às suas despesas e suas obrigações excedem seus recursos para minar sua dignidade. Outro ponto importante é que, se o devedor puder quitar a dívida com meios adequados, ele não será considerado vítima da dívida e, portanto, todos os seus recursos de liquidação da dívida não poderão ser comprometidos e deverão garantir uma vida útil mínima. É a quantidade que garante sua sobrevivência digna. 
Na sociedade moderna, a publicidade surgiu como um ator importante nas relações comerciais e, portanto, é importante informar os consumidores sobre produtos e serviços.

Como resultado, os fornecedores de bens e serviços investem pesadamente em pesquisas para identificar o comportamento de compra do consumidor e traduzir resultados em diferentes estratégias de publicidade. Nesse processo, houve um incentivo para passar de uma pensão para uma empresa de poupança para obter satisfação imediata com os produtos e serviços.

Com base na percepção de Drucker (1975) o marketing não é apenas a realização da venda, mas também consegue compreender e interpretar o consumidor para proporcionar um produto ou serviço que melhor se adapte às suas necessidades de forma que a venda se realize praticamente sozinha.

Existem diversas ferramentas no mercado que podem ser utilizados para atingir o objetivo que o marketing propõe perfeitamente, existem vários trabalhos e técnicas quem podem ser realizadas para a determinação de públicos alvo e da captação deste mercado, da realização manutenção e fidelização dos clientes através da informação e da comunicação determinando um valor superior para o cliente (KOTLER, 2000).

A empresa tem como objetivo transformar os potenciais consumidores em eventuais e a partir disso transformá-los em clientes regulares, porém eles ainda estarão comprando da concorrência, por isso a empresa tem que realizar ações com a ideal de fazer os regulares se tornarem preferenciais, aqueles que a empresa conhece muito bem e os trata da mesma forma.

De acordo com Kotler (2000) "O melhor marketing atualmente em prática é impulsionado pela tecnologia". Com o uso da internet, a comunicação e o entretenimento tecnológico, é possível conhecer o consumidor, estando próximo dele oferecendo um produto ou serviço.

A criação de pseudonecessidades resultantes da estimulação do consumo cria uma sensação de consumo insaciável. Assim, a combinação do crédito como meio de 
promover vendas através da promoção de vendas contribui para o endividamento excessivo, convencendo os consumidores de que eles não precisam e arcando com os custos.

No entanto, vivemos em uma sociedade capitalista e a publicidade é necessária para a distribuição de bens e serviços. Isso é muito importante para a distribuição da riqueza e incentiva a competição em benefício de todos, inclusive dos consumidores. Obviamente, a marca é responsável não apenas pelo superendividamento dos consumidores, mas também pelo seu principal poder de compra, pela necessidade de distribuir parte do risco para o credor, em caso de sérias dificuldades na execução do contrato.

$\mathrm{Na}$ sociedade moderna, a regulação de crédito baseada em informações e transparência nem sempre pode evitar o superendividamento, porque se baseia em um modelo de consumo ideal, operando racionalmente, maximizando benefícios e minimizando custos. Excluindo pressões e incentivos que permeiam o processo de concessão de empréstimos.

\section{CONSIDERAÇÕES FINAIS}

A partir do conteúdo desenvolvido com o objetivo de analisar e apontar os fatores que podem ser relacionados ao superendividamento dos consumidores de baixa renda, é possível concluir que a dívida excessiva da classe social menos favorecida é relacionada a três aspectos principais, sendo legislativo, comercial e social, que resulta em problemas econômicos, sociais e até mesmo constrangimento dessa classe social.

O primeiro fator verificado como atuante no superendividamento é a legislação, atualmente no Brasil, não existe determinação através da lei das especificações relacionadas ao conceito de dívida excessiva, dessa forma é adotada a lei francesa que abrange essa condição, o problema vista é que a lei francesa não possui concordâncias com a lei nacional referente ao código de defesa do consumidor, que resulta em um problema jurídico envolvendo o consumidor e uma grande oferta de 
crédito que não regulada e não é controlada por competência legal, ocorrendo em empréstimos em excessos, principalmente a pessoas de baixa renda que não possuem condições financeiras para consumo de certos produtos.

$\mathrm{Na}$ sequência foi apontado os problemas sociais determinantes de uma classe de poder aquisitivo inferior, que por influência social do desenvolvimento e globalização, sente-se fora dos padrões de vida da sociedade moderna, tendo em vista então uma necessidade de pertencimento social, é realizado a utilização de práticas de oferecimento de crédito em excesso e parcelado sem levar em consideração a soma de juros por trás disso e assim a insuficiência para quitar suas dívidas.

E por fim, existe um aspecto comercial, tendo em vista essa classe social ser um público alvo consideravelmente grande e com alto poder de compra, várias empresas investem em marketing e realizam publicidades com objetivo de atrair consumidores dessa área, ofertando condições facilitadas de pagamentos e produtos de forma mais acessíveis, com o objetivo e propósito único da venda, o que influência os consumidores que não possuem muitas vezes a distinção da não necessidade de compra de certos produtos.

\section{REFERÊNCIAS}

BAUDRILLARD, J. A sociedade de consumo. Lisboa: Arte \& Comunicação, 2007.

BRUSKY, B.; FORTUNA, J. P. Entendendo a demanda para as microfinanças no Brasil: um estudo qualitativo em duas cidades. Rio de Janeiro: BNDES, 2002.

CASTILHOS, R. B. Subindo o morro: consumo, posição social e distinção entre famílias de classes populares. XXXI Encontro da ANPAD. Rio de Janeiro, 22-26 Set, 2007.

DRUCKER, P. F. Administração: Responsabilidades, Tarefas, Práticas. São Paulo: Pioneira, 1975. 
KIRCHNER, F. Os novos fatores teóricos de imputação e concretização do tratamento do superendividamento de pessoas físicas. Revista de Direito do Consumidor. São Paulo: Revista dos Tribunais, v. 65, p. 63-102, jan/mar., 2008.

KOTLER, P. Marketing para o século XXI: como criar, conquistar e dominar mercados. 14. ed. São Paulo: Futura, 2000.

MARQUES, C. L. Contratos no Código de Defesa do Consumidor. 6.ed. Rio de Janeiro: Revista dos Tribunais, 2011.

MARQUES, C. L.; CAVALLAZZI, R. L. Direitos do consumidor endividado: superendivadamento e crédito. São Paulo: Revista dos Tribunais, 2006, p. 14.

NERI, M. C. A Nova Classe Média: O Lado Brilhante dos Pobres. 2010. Disponível em: <www.fgv.br/cps/ncm>. Acessado em: 08/11/2019.

PARENTE, J.; LIMEIRA, T. M. V.; BARKI, E. Varejo para a baixa renda. Porto Alegre: Bookman, 2008.

PAULA, F. M. Informação para fortalecer as relações de consumo. Newsletter do IPEM-SP. № 2. Maio 2011. Disponível em: <http://www.ipem.sp.gov.br/news/maio/>. Acessado em: 08/11/2019.

Enviado: Abril, 2020.

Aprovado: Abril, 2020. 